\title{
Amphiphilic Gemini Pyridinium-mediated incorporation of Zn(II)meso-tetrakis(4-carboxyphenyl)porphyrin into water-soluble gold nanoparticles for photodynamic therapy
}

María E. Alea-Reyes, ${ }^{\text {a,b }}$ Jorge Soriano, ${ }^{c}$ Inma Mora-Espí, ${ }^{c}$ Mafalda Rodrigues, ${ }^{\text {a,b }}$ David A. Russell, ${ }^{\mathrm{d}}$ Leonardo Barrios, ${ }^{\mathrm{c}}$ and Lluïsa Pérez-García*a,b,1

a. Departament de Farmacologia, Toxicologia i Química Terapèutica, Universitat de Barcelona, Avda. Joan XXIII 27-31, 08028 Barcelona, Spain.

E-mail: mlperez@ub.edu

b. Institut de Nanociència i Nanotecnologia UB (IN2UB), Universitat de Barcelona, Avda. Joan XXIII 27-31, 08028 Barcelona, Spain.

c. Departament de Biologia Cel-lular, Fisiologia i Immunologia. Universitat Autònoma de Barcelona, Spain.

d. School of Chemistry, University of East Anglia, Norwich Research Park, Norwich, Norfolk, NR4 7TJ, UK.

Total number of words: 5564

Total number of figures: 4

Total number of tables: 0

\footnotetext{
${ }^{1}$ Present address: School of Pharmacy, The University of Nottingham, University Park, Nottingham, NG7 2RD, UK
} 


\section{Abstract:}

$\mathrm{Zn}$-containing porphyrins are intensely investigated for their ability to form reactive oxygen species and thereby being potent photosensitizers for use in photodynamic therapy (PDT). Some of the drawbacks of the PDT approach, such as unspecific distribution, could be addressed by means of photosensitizer drug delivery systems. In this work, we synthesize and characterize new water-soluble gold nanoparticles (GNP) stabilized by a mixture of a polyethyleneglycol-containing thiol (to improve water solubility) and a new amphiphilic gemini-type pyridinium salt, which also acts as promotor of the incorporation of the anionic photosensitizer Na-ZnTCPP into the GNP. The obtained GNP have sizes between 7-10 nm, as observed by Transmission Electron Microscopy. The incorporation of the photosensitizer caused an increase in the hydrodynamic size, detected by Dynamic Light Scattering, as well as a shift in the Surface Plasmon Resonance peak on the GNP UV-visible absorption spectra. The presence of the photosensitizer in the GNP was corroborated using Fluorescence Spectroscopy. The amount of Na-ZnTCPP was found to be 327 molecules per GNP. The porphyrincontaining Na-ZnTCPP-1·GNP showed good enhanced ability to produce singlet oxygen, compared to free Na-ZnTCPP. Their cytotoxicity and phototoxicity were investigated in vitro using two different human breast cell lines, one of tumoral origin (SKBR-3) and another of normal epithelium origin (MCF-10A). SKBR-3 cells showed higher sensitivity to Na-ZnTCCP and Na-ZnTCPP-1·GNP in dark conditions. After irradiation, no significant differences were observed between both cell lines except for $1 \mu \mathrm{M}$ Na-ZnTCCP-1·GNP where SKBR-3 cells were also more sensitive.

Keywords: Gemini pyridinium amphiphiles, water-soluble gold nanoparticles, anionic porphyrin encapsulation, in vitro phototoxicity, photodynamic therapy, MCF-10A and SKBR-3 cell lines 


\section{Introduction}

PDT is an approach of cancer treatment based on the use of specific drugs, called photosensitizers, which can induce cell death after irradiation, due to the formation of reactive oxygen species [1-3]. PDT has several advantages in the treatment of cancer, since it is less invasive, minimizes the secondary effects and allows more localized areas of the body to be treated. The major drawbacks of PDT are the non-specific distribution of the photosensitizer into the body, and the water-solubility of the photosensitizer, which can be low and thus requires a formulation to improve the administration. In particular, porphyrins are one of the most studied photosensitizers in the last years, to be applied in PDT [2,4-7] but also in sensors as hosts for molecular recognition [8,9]. One of the main characteristics of the porphyrin's structure is the possibility to incorporate a metal into its core, in particular bivalent cations such as $\mathrm{Zn}^{2+}, \mathrm{Mg}^{2+}, \mathrm{Co}^{2+}$ or $\mathrm{Fe}^{2+}$. These metalloporphyrins are intensely investigated for their ability to form Reactive Oxygen Species (ROS) and thereby their interest as potent photosensitizers for use in PDT $[6,10]$. Furthermore, metalloporphyrins (especially Zn-containing porphyrin) have shown to be more efficient as photosensitizer in PDT than the metal-free porphyrin [11]. However, they frequently present low water solubility, which results in low distribution and consequently low efficiency. One way to overcome this drawback is by conjugating the molecule with a system that is used as vehicle.

In the last years, nanostructured systems have raised huge interest in the biomedical field because of their biocompatibility and the potential application as delivery agents for therapy $[1,12,13]$. One example is the use of such vehicles to target cells in cancer therapy [14]. One of the most studied systems in drug delivery is GNP $[15,16]$, and the use of 
nanoparticles incorporating photosensitizers to improve their specificity in PDT has been reported $[5,6,17,18]$.

For the synthesis of organic and water soluble GNP, different types of ligands have been studied as stabilizers, like water-soluble polymers [19], amino acid based amphiphiles [20] or peptides [21]. The use of pyridinium salts as stabilizer agents of GNP has also been reported [22]. On the other hand, gemini surfactants display excellent properties in the preparation and stabilization of monodisperse GNP (organic and water soluble GNP) $[13,23,24]$. However, to the best of our knowledge, the synthesis and stabilization of GNP coated with pyridinium-based gemini amphiphiles and the incorporation of metalloporphyrins into such systems has not yet been reported. In this context, this study describes the methodology for the synthesis of pyridinium-coated GNP, based on a monophasic method, where the gemini-pyridinium amphiphile $\mathbf{1 \cdot 2 B r}$ acts as a promoter, a stabilizer agent as well as a host for the subsequent incorporation of the anionic photosensitizer Na-ZnTCPP into the Na-ZnTCPP, 1·GNP (Figure 1). The new watersoluble GNP were characterized using UV-visible Absorption Spectroscopy, Transmission Electron Microscopy (TEM), Dynamic Light Scattering (DLS) and Fluorescence Spectroscopy. Furthermore, the production of singlet oxygen after irradiation was measured for the porphyrin Na-ZnTCPP, 1•GNP (a control which does not contain photosensitizer) and Na-ZnTCPP-1 GNP, and the cytotoxicity as well as the phototoxicity of the 1-GNP and Na-ZnTCPP-1·GNP were also analysed in two different Human Breast cell lines, one of tumoral origin (SKBR-3) and one of normal epithelium origin (MCF-10A).

\section{Materials and methods}

Materials: Ethanol (EtOH), methanol $(\mathrm{MeOH})$, sodium borohydride $\left(\mathrm{NaBH}_{4}\right)$, gold (III) chloride trihydrate $\left(\mathrm{HAuCl}_{4} \cdot 3 \mathrm{H}_{2} \mathrm{O}\right)$ and 9,10-anthracenediyl-bis(methylene)dimalonic 
acid (ABMA) were purchased from Sigma-Aldrich (Germany). $\alpha$-thio- $\omega$-carboxypolyethylene glycol (HS-C $\left.11-(\mathrm{EG})_{6}-\mathrm{COOH}\right)$ was purchased from Prochimia (France).

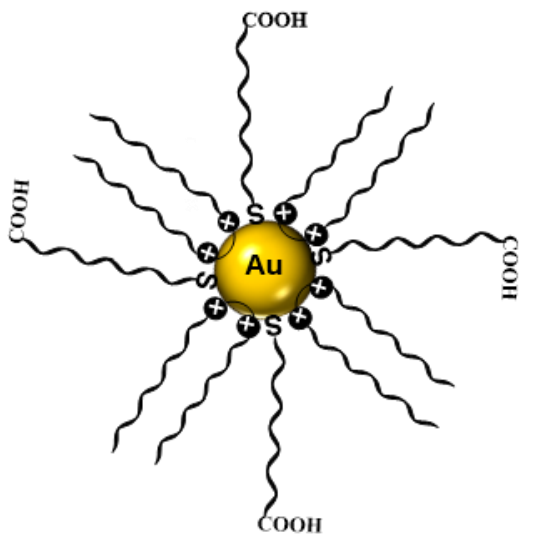

1. GNP

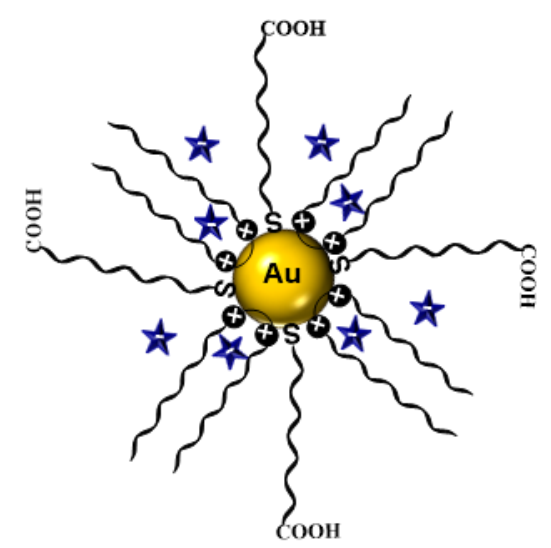

Na-ZnTCPP-1-GNP

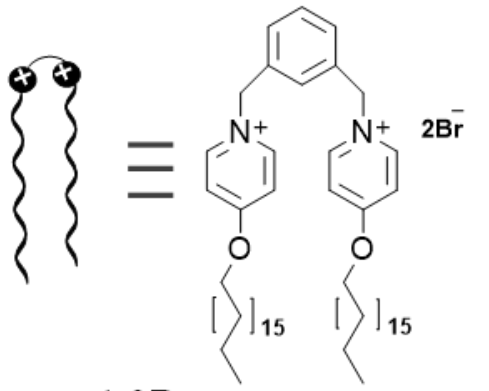

$1 \cdot 2 \mathrm{Br}$

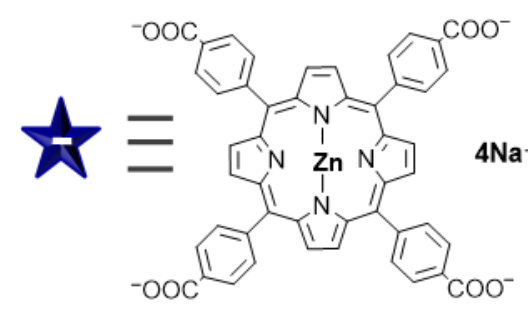

Na-ZnTCPP

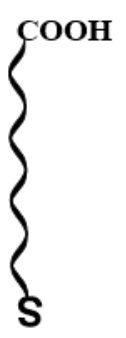

HS- $\mathrm{C}_{11}-(\mathrm{EG})_{6}-\mathrm{COOH}$

Figure 1. Schematic representation of Na-ZnTCPP-1·GNP.

\section{Synthesis of compounds $1 \cdot 2 \mathrm{Br}$ and $\mathrm{Na}-\mathrm{ZnTCPP}$}

The synthesis and characterization of bis-pyridinium salt $\mathbf{1} \cdot \mathbf{2 B r}$ follows a previously reported procedure for imidazolium analogues [23], ; in the case of the porphyrin NaZnTCPP they are explained in detail in the Supplementary Material (Section 1).

\section{Synthesis of water-soluble gold nanoparticles $1 \cdot G N P$ and Na-ZnTCPP-1·GNP}

A solution of $\alpha$-thio- $\omega$-carboxy-polyethylene glycol $(1.3 \mathrm{mg}, 0.0024 \mathrm{mmol})$ in water (1 $\mathrm{mL})$ and a solution of bis-pyridinium salt $\mathbf{1} \cdot \mathbf{2 B r}(5 \mathrm{mg}, 0.0052 \mathrm{mmol})$ in EtOH $(2 \mathrm{~mL})$ were added to a stirred solution of $\mathrm{HAuCl}_{4} \cdot 3 \mathrm{H}_{2} \mathrm{O}(6.7 \mathrm{mg}, 0.017 \mathrm{mmol})$ in water $(1 \mathrm{~mL})$. $\mathrm{NaBH}_{4}(3.3 \mathrm{mg}, 0.087 \mathrm{mmol})$ in water $(1 \mathrm{~mL})$ was added dropwise to the mixture at room temperature. The stirring continued for $24 \mathrm{~h}$ in the dark at room temperature. After this 
time the solvent was removed in a rotary evaporator, and the red residue was purified by multiple cycles of washing with EtOH (3x $1 \mathrm{~mL})$ and water $(3 \times 1 \mathrm{~mL})$ and centrifugation (14000 rpm, $17 \mathrm{~min}$ at $15^{\circ} \mathrm{C}$ ). The new water-soluble GNP were named 1·GNP. For the incorporation of the porphyrin, a solution of Na-ZnTCPP (2 mg, $0.0021 \mathrm{mmol})$ in water ( $2 \mathrm{~mL})$ was added to a stirred solution of $10 \mathrm{ml}$ of $\mathbf{1} \cdot \mathbf{G N P}\left(3 \times 10^{-3} \mu \mathrm{M}\right)$ in water. The stirring continued for $24 \mathrm{~h}$ in the dark at room temperature. The solvent was removed in a rotary evaporator, followed by multiple cycles of washing with water $(5 \times 1 \mathrm{~mL})$ and centrifugation $\left(14000 \mathrm{rpm}, 17 \mathrm{~min}\right.$ at $\left.15^{\circ} \mathrm{C}\right)$, in order to eliminate the unbound porphyrin Na-ZnTCPP. These gold nanoparticles, named Na-ZnTCPP-1·GNP) were obtained at the concentration of $2.9 \times 10^{-3} \mu \mathrm{M}$.

The GNP were characterized using the following techniques: UV-visible absorption spectra were recorded on a UV-1800 Shimadzu UV Spectrophotometer, using quartz cuvettes with a $1 \mathrm{~cm}$ path length. Fluorescence excitation and emission spectra were recorded on a Hitachi F-4500 Fluorescence Spectrometer, using quartz cuvettes with a 1 $\mathrm{cm}$ path length. TEM was performed at the Centres Científics i Tecnològics de la Universitat de Barcelona (CCiT-UB). The samples were prepared by drop casting a $2 \mathrm{x}$ $10^{-3} \mu \mathrm{M}$ aqueous solution of $\mathbf{1 \cdot G N P}$ or Na-ZnTCPP-1· GNP over a carbon-coated copper grid, and were observed using a Tecnai SPIRIT Microscope (FEI Co.) at $120 \mathrm{kV}$. The images were captured by a Megaview III camera and digitalized with the iTEM program. The size of the GNP core was measured with ImageJ. DLS analysis was carried out using a Zetasizer Nano ZS series (Malvern Instruments) from Departament de Farmàcia, Tecnologia Farmacèutica i Fisicoquímica at the Universitat de Barcelona.

\section{Singlet Oxygen production of Na-ZnTCPP and Na-ZnTCPP-1 GNP}

In a quartz cuvette, $3 \mu \mathrm{L}$ of a solution of ABMA $(0.2 \mathrm{mg}, 0.51 \mathrm{mM})$ in $\mathrm{MeOH}(1 \mathrm{~mL})$ was added to either Na-ZnTCPP $(4.34 \mu \mathrm{L}, 3 \mu \mathrm{M})$ or Na-ZnTCPP-1·GNP $(485 \mu \mathrm{L}, 3$ 
$\mu \mathrm{M}$ of incorporated porphyrin) in water. The final volume $(1.5 \mathrm{~mL})$ in the cuvettes was completed with water and the solutions were thoroughly stirred. A light source in the range between 400 and $500 \mathrm{~nm}$ was used to irradiate the mixture during $4 \mathrm{~h}$, using a laser power of $0.16 \mathrm{mw} / \mathrm{cm}^{2}$. The laser was located $3 \mathrm{~cm}$ away from each cuvette. Fluorescence emission spectra were recorded every hour, in the range of $390-600 \mathrm{~nm}$, and singlet oxygen production was determined by the decrease of the fluorescence intensity of ABMA at $431 \mathrm{~nm}$.

\section{Cell culture}

All experiments were performed with two human mammary epithelial cell lines, one with non-tumorigenic origin (MCF-10A) and another tumorigenic (SKBR-3). Both cell lines were purchased from American Type Culture Collection (ATCC, Manassas, VA, USA). MCF-10A cells were cultured in DMEM/F12 (Gibco, Paisley, United Kingdom) supplemented with 5\% horse serum (Gibco), $20 \mathrm{ng} / \mathrm{ml}$ epidermal growth factor (Gibco), $0.5 \mathrm{mg} / \mathrm{ml}$ hydrocortisone (Sigma-Aldrich), $100 \mathrm{ng} / \mathrm{ml}$ cholera toxin (Sigma-Aldrich) and $10 \mu \mathrm{g} / \mathrm{ml}$ insulin (Gibco). SKBR-3 cells were cultured in McCoy's 5A modified medium (Gibco) supplemented with 10\% fetal bovine serum (Gibco). Both cell lines were maintained at $37^{\circ} \mathrm{C}$ and $5 \% \mathrm{CO}_{2}$ (standard conditions).

For each experiment, cells were seeded in 24-well dishes, with or without coverslips, at a density of 50,000 cells/well. Treatments were performed $24 \mathrm{~h}$ after seeding.

\section{Photodynamic treatments}

Cells were incubated in serum-free medium with different concentrations of Na-ZnTCPP (1 and $3 \mu \mathrm{M}), \mathbf{1} \cdot \mathbf{G N P}(70$ and $200 \mu \mathrm{g} / \mathrm{ml})$ or Na-ZnTCPP-1·GNP $(1$ and $3 \mu \mathrm{M}$, corresponding to 70 and $200 \mu \mathrm{g} / \mathrm{ml}$ of $\mathbf{1 \cdot G N P}$ respectively) for $24 \mathrm{~h}$. Afterwards, cells were washed thrice with Phosphate-Buffered Saline (PBS) and maintained in culture medium during irradiation and post-treatment. Irradiation was performed for $10 \mathrm{~min}$ using 
a PhotoActivation Universal Light device (PAUL, GenIUL, Barcelona, Spain), in the range of $620-630 \mathrm{~nm}$ (red light) and with a mean intensity of $55 \mathrm{~mW} / \mathrm{cm}^{2}$.

To evaluate the toxicity of Na-ZnTCPP and Na-ZnTCPP-1.GNP in absence of irradiation, cells were also incubated in the presence of both compounds as described above and were kept in dark conditions (Dark toxicity, DT).

\section{In vitro cytotoxicity assay}

Cell viability was evaluated $24 \mathrm{~h}$ after treatments by the 3-(4,5-dimethylthiazol-2-yl)2,5diphenyltetrazolium bromide (MTT) assay (Sigma-Aldrich). The absorbance was recorded at $540 \mathrm{~nm}$ using a Victor 3 Multilabel Plate Reader (PerkinElmer, Waltham, MA, USA). For each treatment, viability was calculated as the absorbance of treated cells normalized to control conditions. Three independent experiments were performed in each case.

All graphics and statistical analyses were performed using GraphPad Prism version 6.01 for Windows, (GraphPad Software, La Jolla, California, USA). Results were analysed through a two-way ANOVA with a minimal significance level set at $\mathrm{P} \leq 0.05$.

\section{Actin microfilaments and nuclear staining}

At $24 \mathrm{~h}$ after photodynamic treatments, cells were fixed with $4 \%$ paraformaldehyde in PBS for 15 min, permeabilized with $0,1 \%$ Triton X-100 (Sigma-Aldrich) in PBS and incubated with Alexa-Fluor®594-conjugated Phalloidin (Invitrogen) for 45 min. Next, cells were washed thrice and nuclei were counterstained with $5 \mu \mathrm{g} / \mathrm{ml}$ Hoechst $33258(\mathrm{H}-$ 33258, Life Technologies, Carlsbad, CA) for $3 \mathrm{~min}$. Preparations were mounted in ProLong Gold (Life Technologies) and observed under a Confocal Laser Scanning Microscope (CLSM, Olympus XT7) from the Servei de Microscòpia at the Universitat Autònoma de Barcelona. 


\section{Results and discussion}

\section{Synthesis and characterization of $1 \cdot 2 \mathrm{Br}$ and Na-ZnTCPP}

The bis-pyridinium salt $\mathbf{1} \cdot \mathbf{2 B r}$ was selected to be used as stabilizer agent of GNP and also acts as host in the subsequent incorporation of the photosensitizer Na-ZnTCPP.

According to previous reports by our group [12,13,23], GNP stabilized with gemini imidazolium based amphiphiles showed good ability to incorporate anionic molecules. The gemini pyridinium analogue $\mathbf{1} \cdot \mathbf{2 B r}$ is expected to expand the range of non-covalent interaction with anionic species. Consequently, the anionic porphyrin Na-ZnTCPP was selected in this work to be incorporated on the synthesized pyridinium-based GNP. NaZnTCPP was synthesized according to modification of previously reported methods $[25,26]$. The metalation step was monitored by UV-visible Absorption Spectroscopy: the four $\mathrm{Q}$ bands from the free base porphyrin are replaced by two $\mathrm{Q}$ bands of the corresponding $\mathrm{Zn}$ (II) derivative, indicating the metalation process is complete in $24 \mathrm{~h}$. Na-ZnTCPP was obtained with a 94\% yield (synthesis and characterization are explained in detail in Supplementary Material Section 1, Scheme S1 and Figures S1-S4). Synthesis of water-soluble gold nanoparticles $1 \cdot G N P$ and Na-ZnTCPP-1·GNP

In order to obtain nanoparticles with a high potential use in biomedical applications, the synthesized GNP should be water soluble. For this reason, we used a mixture of the gemini pyridinium-based amphiphilic ligand $\mathbf{1} \cdot \mathbf{2 B r}$ and the thiolated polyethyleneglycol derivative $\alpha$-thio- $\omega$-carboxy-polyethylene glycol for the formation of all the new GNP. Briefly, the GNP were synthesized by preparing small amounts of $\alpha$-thio- $\omega$-carboxypolyethylene glycol in EtOH, to favour the solubility in water of synthesized GNP, and $\mathbf{1} \cdot \mathbf{2 B r}$ as stabilizer agent and anionic binder; then adding an aqueous solution of $\mathrm{HAuCl}_{4}$ and then the reducing agent $\mathrm{NaBH}_{4}$. The obtained GNP were purified by sequential 
washing and centrifugation, and were named 1-GNP. These new water-soluble 1・GNP were later used as a model colloid for the biological control experiments.

In this work, we selected the anionic porphyrin Na-ZnTCPP as photosensitizer to be incorporate into the gemini-pyridinium coated GNP. This porphyrin has already shown high potential for use in PDT $[27,28]$ due to its water solubility, and its negative charges allows its noncovalent incorporation into cationic GNP, thus providing an alternative delivery strategy with the potential to avoid photosensitizer leakage and processing issues, which has been reported for different drugs [29,30]. The anionic porphyrin NaZnTCPP was incorporated on 1·GNP, and the Na-ZnTCPP containing GNP were named Na-ZnTCPP-1·GNP. The schematic representation of 1·GNP and Na-ZnTCPP1. GNP can be seen in Figure 1.

\section{Characterization of Na-ZnTCPP, $1 \cdot G N P$ and Na-ZnTCPP-1·GNP}

The formation of 1.GNP and the incorporation of the porphyrin Na-ZnTCPP into the Na-ZnTCPP-1 -GNP were confirmed by UV-visible Absorption Spectroscopy (Figure 2 a)). The UV-visible absorption spectra were recorded in water. The free porphyrin NaZnTCPP showed the typical Soret band at $423 \mathrm{~nm}$ and two Q bands at 557 and $593 \mathrm{~nm}$. In the case of $\mathbf{1 \cdot G N P}$, the typical Surface Plasmon Resonance (SPR) band of the GNP was observed near $520 \mathrm{~nm}$, while the Na-ZnTCPP-1·GNP show a peak at $530 \mathrm{~nm}$, and also a peak at $c a .430 \mathrm{~nm}$ that corresponds to the porphyrin Na-ZnTCPP Soret band. In addition, the two typical Zinc porphyrin Q bands can be identified in the Na-ZnTCPP1.GNP spectrum, at 566 and $610 \mathrm{~nm}$. It is noteworthy the observation of shifts in the peaks when comparing: a) the Soret band wavelength of the free porphyrin Na-ZnTCPP $(423 \mathrm{~nm})$ with the porphyrin incorporated into Na-ZnTCPP-1·GNP $(430 \mathrm{~nm}), \mathrm{b})$ the typical SPR band of 1·GNP $(520 \mathrm{~nm})$ and of Na-ZnTCPP-1·GNP $(530 \mathrm{~nm})$ and c) the Q bands of the free porphyrin (557 and 593) and the porphyrin incorporated in the Na- 
ZnTCPP-1·GNP (566 and $610 \mathrm{~nm}$ ). These shifts in the characteristic peaks are probably due to the influence of the electrostatic interaction established between the positive charges of the pyridinium salt $\mathbf{1} \cdot \mathbf{2 B r}$ and the negative charges of the porphyrin NaZnTCPP present in the Na-ZnTCPP-1 GNP, where the alkyl chains may create a pocket where the porphyrin is introduced in the proximity of the polar head, but also the porphyrin may be localized outside the pocket but interacting with the positive charge of the $\mathbf{1} \cdot \mathbf{2 B r}$.

1-GNP and Na-ZnTCPP-1.GNP were characterized using TEM to study their morphology and their size distribution for $\mathbf{1} \cdot \mathbf{G N P}$ and Na-ZnTCPP-1·GNP as seen in Figure 2 (see Supplementary Material Section 2 Figure S5). The analysed GNP display a spherical shape and show sizes between 7-10 nm. In both cases, the particles are well separated and in very few cases show short distances between them, indicating they are well dispersed in water and that the incorporation of Na-ZnTCPP did not cause aggregation.

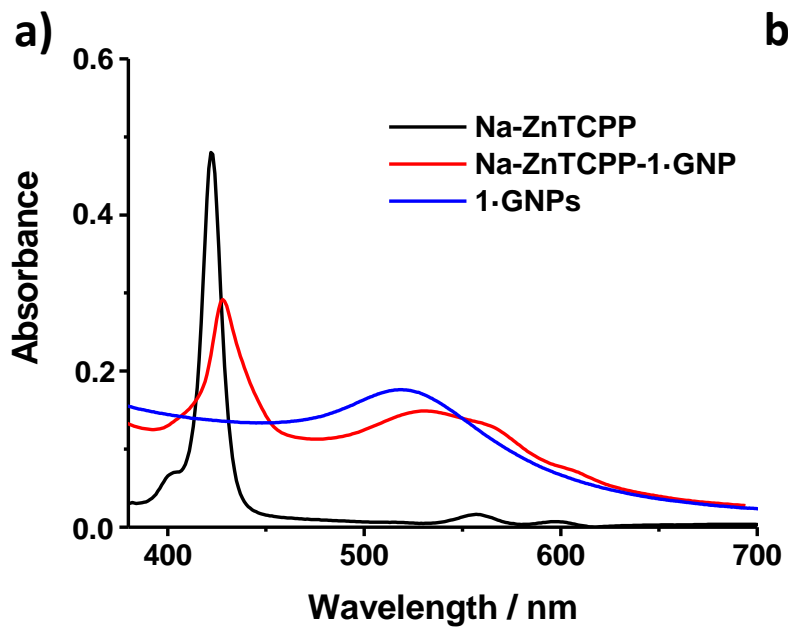

b)

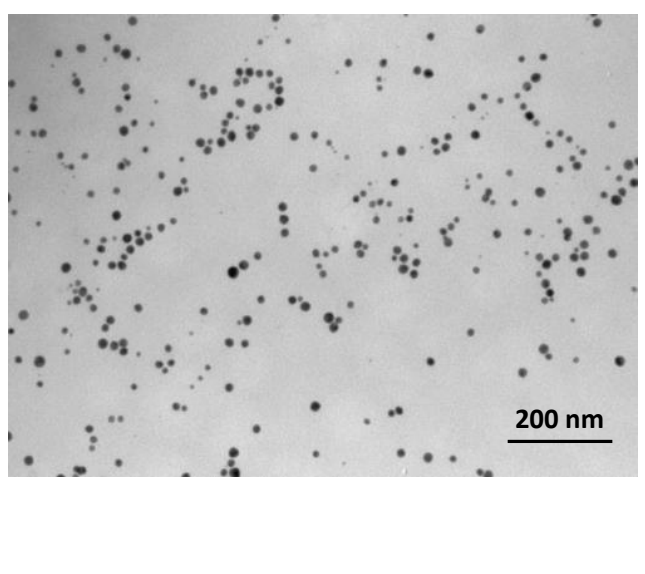

Figure 2. a) UV-visible absorption spectra of the free porphyrin Na-ZnTCPP, 1-GNP and Na-ZnTCPP-1.GNP, recorded in water at $25{ }^{\circ} \mathrm{C}$ and b) Transmission electronic microscopy (TEM) image of Na-ZnTCPP-1·GNP. 
1.GNP and Na-ZnTCPP-1·GNP were also analysed using DLS. Both GNP proved stable in solution, since no aggregation occurred, and have a low polydispersity index, with values of 0.13 and 0.21 , respectively. The average size measured was of $10.2 \mathrm{~nm}$ for 1·GNP and $15.3 \mathrm{~nm}$ for Na-ZnTCPP-1-GNP. DLS measured the hydrodynamic diameter that includes not only the core but also the alkyl chains of the $\mathbf{1} \cdot \mathbf{2 B r}$, the thiol $\alpha$-thio- $\omega$-carboxy-polyethylene glycol and the molecules of the incorporated porphyrin Na-ZnTCPP. The sizes obtained by DLS for $\mathbf{1} \cdot$ GNP and Na-ZnTCPP-1·GNP are different, which may be due to the incorporation of the porphyrin in the organic layer around the gold core that leads to an increase in the diameter of the nanoparticles NaZnTCPP-1·GNP in relation with $1 \cdot$ GNP.

Fluorescence spectroscopy was also used to identify the incorporation of the porphyrin into the synthesized Na-ZnTCPP-1·GNP. Fluorescence emission spectra were recorded in water for the free porphyrin Na-ZnTCPP and Na-ZnTCPP-1·GNP (see Supplementary Material Section 2 Figure S6), and both spectra exhibit two peaks at $c a$. $\lambda 606 \mathrm{~nm}$ and $\lambda 660 \mathrm{~nm}$ following excitation at $\lambda 421 \mathrm{~nm}$, which is consistent with reports for Zn-porphyrin derivatives [31]. These results confirm the incorporation of NaZnTCPP into the Na-ZnTCPP-1.GNP, and also demonstrate that the fluorescence emission of the photosensitizer is not affected significantly when the porphyrin is linked to the GNP.

\section{Quantification of Na-ZnTCPP incorporated into Na-ZnTCPP-1·GNP}

The quantification of the amount of porphyrin Na-ZnTCPP per Na-ZnTCPP-1 GNP was performed using UV-vis absorption spectroscopy and taking into account the diameter size of Na-ZnTCPP-1·GNP, as previously determined by TEM. The wavelength selected to determine the amount of Na-ZNTCPP incorporated into NaZnTCPP-1 GNP was that corresponding to the Soret band $(430 \mathrm{~nm})$ because it was the 
most intense peak corresponding to the porphyrin. First, a calibration curve of NaZnTCPP was obtained using a range of concentrations between $0.5 \mu \mathrm{M}$ and $10 \mu \mathrm{M}$ (see Supplementary Material Section 3 Figure S7), in order to calculate its extinction coefficient $(\varepsilon)$, that was found to be $\left(\varepsilon_{423}\right)=355600 \mathrm{M}^{-1} \mathrm{~cm}^{-1}$. The Na-ZnTCPP-1·GNP UV-Visible absorption spectrum shows quite broad absorption bands and in order to normalize the Soret band absorbance value, a subtraction between the Soret band peak and the absorbance of the porphyrin into Na-ZnTCPP-1·GNP sloping background at 470 nm was calculated (see Supplementary Material Section 3 Figure S8). Accordingly, we calculated that the molarity of the Na-ZnTCPP present on the Na-ZnTCPP-1·GNP colloidal suspension corresponds to $0.94 \mu \mathrm{M}$. Consequently, in order to obtain the number of porphyrin molecules per Na-ZnTCPP-1-GNP, the concentration of the Na-ZnTCPP1. GNP colloidal suspension was calculated using the diameter obtained by TEM and its UV absorbance value at $450 \mathrm{~nm}$, obtaining a value of $2.9 \times 10^{-3} \mu \mathrm{M}$. Taking into account the suspension volume $(3 \mathrm{~mL})$ and the Avogadro's number, we obtain the number of porphyrin molecules immobilized on the Na-ZnTCPP-1·GNP surface, which corresponds to 327 molecules of Na-ZnTCPP incorporated per GNP (see Supplementary Material Section 3 Table S1).

\section{Singlet oxygen production of Na-ZnTCPP and Na-ZnTCPP-1·GNP}

Singlet oxygen $\left({ }^{1} \mathrm{O}_{2}\right)$ production was examined using water soluble ABMA as a probe. Upon reaction with ${ }^{1} \mathrm{O}_{2}$, ABMA forms a non-fluorescent 9,10-endoperoxide product [32], resulting in the decay of the fluorescence of ABMA, which can be easily monitored using fluorescence spectroscopy. The photosensitizer Na-ZnTCPP, both free in aqueous solution or incorporated into Na-ZnTCPP-1·GNP in water, was irradiated for $4 \mathrm{~h}$ with continuous stirring in the presence of a solution of ABMA in $\mathrm{MeOH}$, using a blue light source which excites the Soret band of the porphyrin (near $420 \mathrm{~nm}$ ). The fluorescence 
emission spectra were recorded every hour, in the range of 390-600 nm, and the singlet oxygen production was determined by the decrease of the fluorescence intensity of ABMA (see Supplementary Material Section 4 Figure S9). A similar protocol was followed to quantify the ${ }^{1} \mathrm{O}_{2}$ production by $\mathbf{1 \cdot G N P}$ as control. The percentage decay of ABMA fluorescence emission band at $\lambda 431 \mathrm{~nm}$ following irradiation of Na-ZnTCPP, Na-ZnTCPP-1·GNP and 1·GNP is shown in Supplementary Material Section 4 Figure S10. It can be clearly observed the fluorescence decay in the case of Na-ZnTCPP and Na-ZnTCPP-1·GNP, demonstrating the formation of singlet oxygen. However, when ABMA solution was irradiated under the same conditions in the presence of $\mathbf{1} \cdot \mathbf{G N P}$, without any porphyrin, a negligible decay in the ABMA fluorescence was observed, confirming that the singlet oxygen was produced by the photosensitizer Na-ZnTCPP, alone or incorporated in the GNP, upon irradiation. After 4 hours, the percentage of emission decay for ABMA in the presence of Na-ZnTCPP and Na-ZnTCPP-1.GNP was $30 \%$ and $49 \%$, respectively, indicating that the porphyrin incorporated into NaZnTCPP-1-GNP is more efficient to produce the ${ }^{1} \mathrm{O}_{2}$ than the free porphyrin in solution. To further compare the ability to produce singlet oxygen by Na-ZnTCPP both free in solution and incorporated in the Na-ZnTCPP-1.GNP, the maximum rate of ABMA photobleaching was normalized with the concentration of the photosensitizer NaZnTCPP $(3 \mu \mathrm{M})$ (see Supplementary Material Section 4 Equation S1). The calculated maximum rates of ABMA photobleaching upon irradiation were $0.03 \% I F / \mathrm{min} \cdot \mu \mathrm{M}$ obtained for the free porphyrin Na-ZnTCPP, and $0.08 \% I F / \mathrm{min} \cdot \mu \mathrm{M}$ obtained for the porphyrin-containing Na-ZnTCPP-1·GNP, where $I F$ is the Intensity of Fluorescence (see Supplementary Material Section 4 Figure S11). These results demonstrate that the porphyrin Na-ZnTCPP resulted more effective when immobilized on GNP rather than free in solution, with an increased singlet oxygen production, a feature previously 
reported for similar systems $[2,33]$. This fact is even more remarkable considering that the photobleaching of the porphyrin incorporated into GNP was measured in aqueous solution, where oxygen is much less soluble and usually leads to a less significant effect for this type of measurement because of the shorter lifetime of singlet oxygen in water [34].

Although there are examples in the literature reporting similar strategies to probe the singlet oxygen production, a direct comparison is difficult, because different conditions are used: for example, different photosensitizers (phtalocyanines [33], porphyrin [2,35] and metalloporphyrins [36]), light sources, irradiation times, different vehicles and different anthracene derivatives, such as ABMA, DMA (9,10-dimethyl-anthracene) and ADPA (9-[(2,2'-dipicolylamino)methyl]anthracene)[32,35,37], used to detect reactive oxygen species in particular singlet oxygen.

\section{Photodynamic effect of Na-ZnTCPP on cell cultures}

Cell viability $24 \mathrm{~h}$ after treatments with Na-ZnTCPP was evaluated by MTT assay (see Supplementary Material Section 5 Figure S12). In dark conditions, incubation with $1 \mu \mathrm{M}$ Na-ZnTCPP did not significantly modify the viability of MCF-10A cells, whereas treatments with a higher concentration ( $3 \mu \mathrm{M}$ Na-ZnTCPP) induced a decrease in cell survival. In contrast, SKBR-3 cells showed a decrease in cell viability at both concentrations. When irradiated (10 min), both cell lines, treated either with 1 and $3 \mu \mathrm{M}$ Na-ZnTCPP, showed a significant decrease in cell survival, but without significant differences between both cell lines, in accordance to preliminary data [38].

Actin microfilaments and nuclear morphology were observed by Alexa-Fluor ${ }^{\circledR 594-}$ conjugated Phalloidin and H-33258 staining. In absence of irradiation, both cell lines treated either with 1 or $3 \mu \mathrm{M}$ Na-ZnTCPP did not present actin microfilaments or nuclear alterations (Figure 3 a) and c)). In contrast, after $10 \mathrm{~min}$ of irradiation, and at both 
concentrations of Na-ZnTCPP, MCF-10A cells showed a high disorganization of actin microfilaments and no stress fibres were observed, although nuclei remained unaltered (Figure 3 b)). SKBR-3 cells after irradiation showed a similar disorganization of the actin cytoskeleton but some apoptotic or necrotic nuclei were observed (Figure $3 \mathrm{~d}$ )).

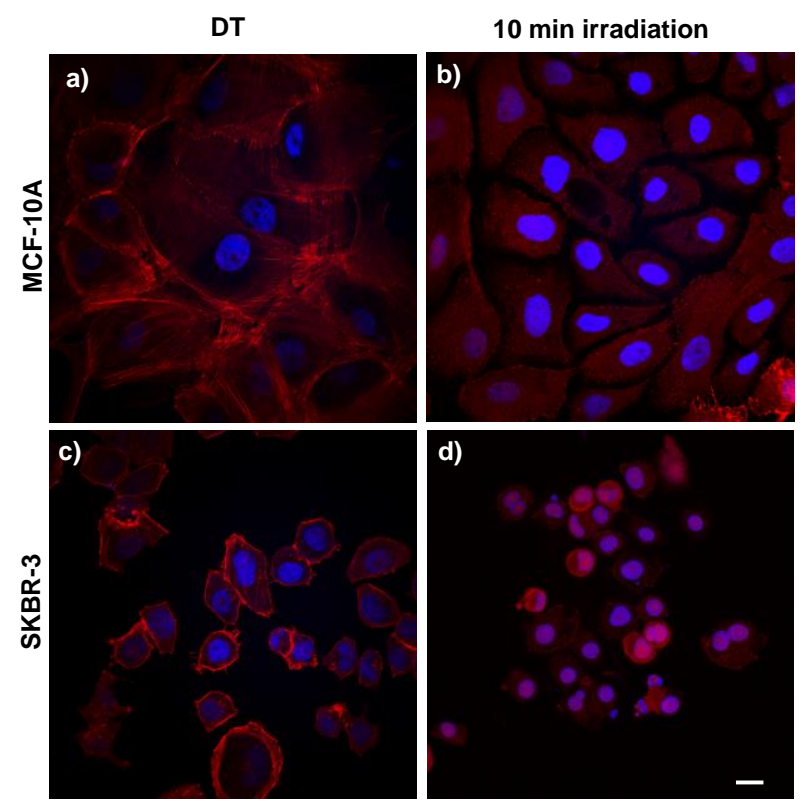

Figure 3. Cells incubated with $3 \mu \mathrm{M}$ Na-ZnTCPP for $24 \mathrm{~h}$, kept in darkness (DT) and processed $24 \mathrm{~h}$ after with Alexa-Fluor ${ }^{\circledR 594-c o n j u g a t e d ~ P h a l l o i d i n ~(r e d) ~ a n d ~}$ counterstained with Hoechst-33258 (blue) a) and c). Cells incubated with $3 \mu \mathrm{M}$ NaZnTCPP for $24 \mathrm{~h}$, irradiated $10 \mathrm{~min}$ and processed $24 \mathrm{~h}$ after photodynamic treatments with Alexa-Fluor®594-conjugated Phalloidin (red) and counterstained with Hoechst33258 (blue) b) and d). Scale bar, $10 \mu \mathrm{m}$.

\section{Photodynamic effect of Na-ZnTCPP-1·GNP on cell cultures}

Prior to the phototoxicity study of Na-ZnTCPP-1.GNP, the uptake and cytotoxicity of 1.GNP in MCF-10A and SKBR-3 cells was evaluated. 1·GNP uptake after $24 \mathrm{~h}$ incubation was observed under bright field microscope (see Supplementary Material 
Section 5 Figure S13 a) and b)). In MCF-10A cells, the majority of nanoparticles were distributed around the nuclei forming aggregates of variable size. In contrast, SKBR-3 cells were able to internalize 1·GNP but in a lesser quantity, and many remained attached to the plasma membrane. The effect of $\mathbf{1 \cdot G N P}$ on cell viability showed that $24 \mathrm{~h}$ after irradiation, the presence of $\mathbf{1}$ GNP did not reduce significantly the viability of MCF-10A cells, but significantly reduced SKBR-3 cells survival at both studied concentrations (70 or $200 \mu \mathrm{g} / \mathrm{ml}$ ), (see Supplementary Material Section 5 Figure S13 c)). Finally, the presence of 1. GNP inside the cells did not alter actin cytoskeleton or nuclear morphology (see Supplementary Material Section 5 Figure S13 d)-g), and under bright field microscope we confirmed that $\mathbf{1 \cdot G N P}$ remained inside the cells, with a similar pattern to that previously described.

The cytotoxicity of Na-ZnTCPP-1.GNP 24 h after treatments was evaluated by MTT assay (see Supplementary Material Section 5 Figure S14). In dark conditions MCF-10A cells viability was not affected at both Na-ZnTCPP-1•GNP concentration. However, SKBR-3 cells showed a concentration-dependent decrease of cell survival. After irradiation, both cell lines showed a decrease in cell viability although MCF-10A treated with $1 \mu \mathrm{M}$ Na-ZnTCPP-1.GNP presented higher resistance to photodynamic treatments than MCF-10A cells treated with $3 \mu \mathrm{M}$ Na-ZnTCPP-1·GNP or SKBR-3 cells subjected to treatments with both concentrations of Na-ZnTCPP-1. GNP.

As observed for 1·GNP, MCF-10A showed a higher uptake of Na-ZnTCPP-1·GNP than SKBR-3 cells (Figure 4 a) and c)). It has been reported that MCF-10A cells can internalize both positively and negatively charged particles, whereas in SKBR-3 cells the uptake of negative charged particles is low $[39,40]$. The differences in cell uptake can be explained because Na-ZnTCPP-1·GNP are negatively charged. After irradiation, most of MCF10A cells treated with $1 \mu \mathrm{M}$ Na-ZnTCPP-1 GNP remained unaltered, but some detached 
and contracted cells were observed (Figure 4 b)). On the contrary, most of the SKBR-3 cells subjected to the same treatments were floating in the medium and showed blebs in their plasma membrane (Figure $4 \mathrm{~d})$ ).
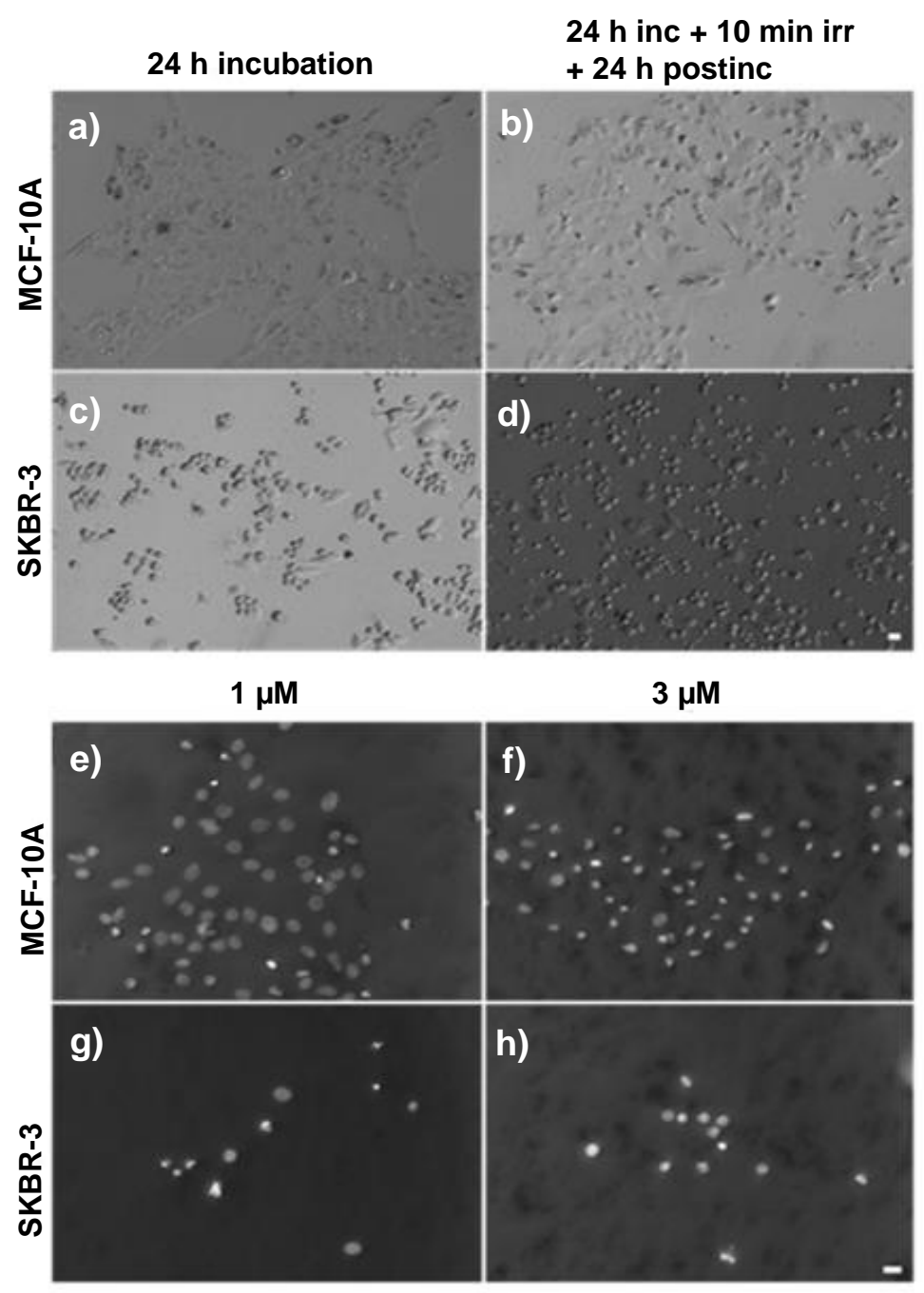

Figure 4. Cells incubated with $1 \mu \mathrm{M}$ Na-ZnTCPP-1·GNP for $24 \mathrm{~h}$ and observed under DIC microscope a) and c). Cells incubated with $1 \mu \mathrm{M}$ Na-ZnTCPP-1·GNP for $24 \mathrm{~h}$, irradiated 10 min with red light and observed after $24 \mathrm{~h}$ under DIC microscope b) and d). Cells incubated with different concentrations of Na-ZnTCPP-1·GNP for $24 \mathrm{~h}$, irradiated 10 min with red light and processed after $24 \mathrm{~h}$ for Hoechst-33258 staining e)-h). Scale bar, $10 \mu \mathrm{m}$. 
Nuclear staining with H-33258 confirms these results: MCF-10A cells treated $1 \mu \mathrm{M}$ NaZnTCPP-1.GNP showed most of the nuclei unaltered, but with some apoptotic or necrotic nuclei (Figure 4 e)). In contrast, the same cells treated with $3 \mu \mathrm{M}$ Na-ZnTCPP1-GNP showed a predominant necrotic morphology (Figure $4 \mathrm{f}$ )). SKBR-3 cells treated with both concentrations of Na-ZnTCPP-1·GNP showed an important decrease in cell density and the cells that remained attached showed necrotic or apoptotic morphology (Figure $4 \mathrm{~g}$ ) and $\mathrm{h})$ ).

\section{Conclusion}

In this work, we successfully prepared new water-soluble 1.GNP based on bispyridinium amphiphiles $\mathbf{1} \cdot \mathbf{2 B r}$ following a monophasic method using as stabilizer agents $\alpha$-thio- $\omega$-carboxy-polyethylene glycol, to make the nanoparticles water soluble, and the pyridinium salt $\mathbf{1} \cdot \mathbf{2 B r}$, which also acted as host to incorporate Na-ZnTCPP in the NaZnTCPP-1 GNP. The obtained porphyrin-loaded GNP are spherical and monodisperse, and the incorporation of the photosensitizer did not cause aggregation, thus suggesting they can be used as essentially single particle delivery system. The incorporation of the Na-ZnTCPP into the Na-ZnTCPP-1.GNP notably increased the capacity of the photosensitizer to generate singlet oxygen, which may be due to an enhancement effect of the GNP gold core on the porphyrin activity. SKBR-3 tumoral cells showed more sensitivity to Na-ZnTCPP-1·GNP, in dark conditions or after irradiation, than MCF-10A non-tumoral cells.

These findings suggest that the synthesized Na-ZnTCPP-1·GNP are a promising nanosystem for PDT. Future work includes the incorporation of antibodies through immobilization using the $\alpha$-thio- $\omega$-carboxy-polyethylene glycol present on the NaZnTCPP-1·GNP, to actively target cancer cells. 


\section{Appendix A. Supplementary data}

Supplementary data related to this article can be found at http://dx.doi.org/10.1016/j.colsurfb.xxxx.xx.xxx.

\section{Acknowledgements}

This work was supported by the EU ERDF (FEDER) funds and the Spanish Government [grants TEC2014-51940-C2-2-R], [MAT2014-57960-C03-3-R] and the Generalitat de Catalunya [2014-SGR-524]. M. E. A-R and I. M-E thank the Universitat de Barcelona and the Spanish Ministerio de Economía, Industria y Competitividad, respectively, for predoctoral grants. The authors wish to thank the Servei de Microscòpia at the Universitat Autonòma de Barcelona.

\section{References}

[1] M. Triesscheijn, P. Baas, J.H.M. Schellens, F.A. Stewart, Oncol., 11 (2006) 10341044.

[2] O. Penon, M.J. Marín, D.A. Russell, L. Pérez-García, J. Colloid Interface Sci., 496 (2017) 100-110.

[3] H.-I. Lee, Y.-J. Kim, Colloids Surfaces B: Biointerfaces, 142 (2016) 182-191.

[4] E.D. Sternberg, D. Dolphin, C. Brückner, C. Brickner, Tetrahedron, 54 (1998) 4151-4202.

[5] O. Penon, T. Patiño, L. Barrios, C. Nogués, D.B. Amabilino, K. Wurst, L. PérezGarcía, ChemistryOpen, 4 (2015) 127-136.

[6] P.M. Antoni, A. Naik, I. Albert, R. Rubbiani, S. Gupta, P. Ruiz-Sanchez, P. Munikorn, J.M.J.M. Mateos, V. Luginbuehl, P. Thamyongkit, U. Ziegler, G. Gasser, G. Jeschke, B. Spingler, Chem. - A Eur. J., 21 (2015) 1179-1183.

[7] Z. Hu, Y. Pan, J. Wang, J. Chen, J. Li, L. Ren, Biomed. Pharmacother., 63 (2009) 155-164.

[8] R. Yang, K. Li, K. Wang, F. Zhao, N. Li, F. Liu, Anal. Chem., 75 (2003) 612-621.

[9] H. Ogoshi, T. Mizutani, Curr. Opin. Chem. Biol., 3 (1999) 736-739. 
[10] L. Jayashankar, B.S. Sundar, R. Vijayaraghavan, K.S. Betanabhatla, C. Ajm, J. Athimoolam, K.S. Saravanan, Pharmacologyonline, 1 (2008) 66-77.

[11] Q. Yu, W.-X. Xu, Y.-H. Yao, Z.-Q. Zhang, S. Sun, J. Li, J. Porphyrins Phthalocyanines, 19 (2015) 1107-1113.

[12] E. Amirthalingam, M. Rodrigues, L. Casal-Dujat, A.C. Calpena, D.B. Amabilino, D. Ramos-López, L. Pérez-García, J. Colloid Interface Sci., 437 (2015) 132-139.

[13] M. Rodrigues, A.C. Calpena, D.B. Amabilino, D. Ramos-López, J. de Lapuente, L. Pérez-García, RSC Adv., 4 (2014) 9279-9287.

[14] T. Stuchinskaya, M. Moreno, M.J. Cook, D.R. Edwards, D.A. Russell, Photochem. Photobiol. Sci., 10 (2011) 822-831.

[15] H. Bessar, I. Venditti, L. Benassi, C. Vaschieri, P. Azzoni, G. Pellacani, C. Magnoni, E. Botti, V. Casagrande, M. Federici, A. Costanzo, L. Fontana, G. Testa, F.F. Mostafa, S.A. Ibrahim, M.V. Russo, I. Fratoddi, Colloids Surfaces B: Biointerfaces, 141 (2016) 141-147.

[16] M. Ganeshkumar, M. Sathishkumar, T. Ponrasu, M.G. Dinesh, L. Suguna, Colloids Surfaces B: Biointerfaces, 106 (2013) 208-216.

[17] G.V. Roblero-Bartolon, E. Ramon-Gallegos, Gac. Med. Mex., 151 (2015) 85-98.

[18] K. Zaruba, J. Kralova, P. Rezanka, P. Pouckova, L. Veverkova, V. Kral, Org. Biomol. Chem., 8 (2010) 3202-3206.

[19] I. Hussain, S. Graham, Z. Wang, B. Tan, D.C. Sherrington, S.P. Rannard, A.I. Cooper, M. Brust, J. Am. Chem. Soc., 127 (2005) 16398-16399.

[20] S. Si, E. Dinda, T.K. Mandal, Chem. Eur. J., 13 (2007) 9850-9861.

[21] R. Lévy, N.T.K. Thanh, R.C. Doty, I. Hussain, R.J. Nichols, D.J. Schiffrin, M. Brust, D.G. Fernig, J. Am. Chem. Soc., 126 (2004) 10076-10084.

[22] K.B. Male, J.J. Li, C.C. Bun, S.C. Ng, J.H.T. Luong, J. Phys. Chem. C., 112 (2008) 443-451.

[23] L. Casal-Dujat, M. Rodrigues, A. Yagüe, A.C. Calpena, D.B. Amabilino, J. González-Linares, M. Borràs, L. Pérez-García, Langmuir, 28 (2012) 2368-2381.

[24] M. Murawska, A. Skrzypczak, M. Kozak, Acta Phys. Pol. A., 121 (2012) 888-892.

[25] M. Mojiri-Foroushani, H. Dehghani, N. Salehi-Vanani, Electrochim. Acta., 92 (2013) 315-322.

[26] Y. Yuan, H. Lu, Z. Ji, J. Zhong, M. Ding, D. Chen, Y. Li, W. Tu, D. Cao, Z. Yu, Z. Zou, Chem. Eng. J., 275 (2015) 8-16. 
[27] N. Siraj, P.E. Kolic, B.P. Regmi, I.M. Warner, Chem. Eur. J., 21 (2015) 1444014446.

[28] P.E. Kolic, N. Siraj, S. Hamdan, B.P. Regmi, I.M. Warner, J. Phys. Chem. C., 120 (2016) 5155-5163.

[29] C.K. Kim, P. Ghosh, C. Pagliuca, Z.J. Zhu, S. Menichetti, V.M. Rotello, J. Am. Chem. Soc., 131 (2009) 1360-1361.

[30] P. Basilion, C. Burda, J Am Chem Soc., 133 (2012) 2583-2591.

[31] V. V. Apanasovich, E.G. Novikov, N.N. Yatskov, R.B.M. Koehorst, T.J. Schaafsma, A. van Hoek, J. Appl. Spectrosc., 66 (1999) 613-616.

[32] M. Wang, L. Huang, S.K. Sharma, S. Jeon, S. Thota, F.F. Sperandio, S. Nayka, J. Chang, M.R. Hamblin, L.Y. Chiang, J. Med. Chem., 55 (2012) 4274-4285.

[33] R. Lin, L. Zhou, Y. Lin, A. Wang, J.H. Zhou, S.H. Wei, Spectroscopy, 26 (2011) 179-185.

[34] R. Battino, T.R. Rettich, T. Tominaga, J. Phys. Chem. Ref. Data., 12 (1983) 163178.

[35] S.J. Mora, M.E. Milanesio, E.N. Durantini, J. Photochem. Photobiol. A Chem., 270 (2013) 75-84.

[36] O. Penon, M.J. Marín, D.A. Russell, L. Pérez-García, J. Colloid Interface Sci., 462 (2016) 154-165.

[37] S. Senthilkumar, R. Hariharan, A. Suganthi, M. Ashokkumar, M. Rajarajan, K. Pitchumani, Powder Technology, 237 (2013) 497-505.

[38] J. Soriano, I. Mora-Espí, M. E. Alea-Reyes, L. Pérez-García, L. Barrios, E. Ibáñez, C. Nogués, Sci. Rep., 7 (2017) 41340.

[39] T. Patiño, J. Soriano, E. Amirthalingam, S. Durán, A. González-Campo, M. Duch, E. Ibáñez, L. Barrios, J.A. Plaza, L. Pérez-García, C. Nogués, Nanoscale, 8 (2016) 8773-8783.

[40] T. Patiño, J. Soriano, L. Barrios, E. Ibáñez, C. Nogués, Sci. Rep., 5 (2015) 11371. 